\title{
UNMET NEEDS AMONG BREAST CANCER PATIENTS IN A DEVELOPING COUNTRY AND SUPPORTIVE CARE NEEDS SURVEY VALIDATION
}

\author{
Carmen L. Gálvez-Hernández ${ }^{1,2,3}$, Allison Boyes ${ }^{4}$, Andrea Ortega-Mondragón ${ }^{3}$; \\ Andrea G. Romo-González ${ }^{3}$, Alejandro Mohar ${ }^{2,5}$, Fernanda Mesa-Chavez ${ }^{2,6}$, \\ LUIS OÑate-OCAÑA ${ }^{5}$, AND Cynthia Villarreal-Garza ${ }^{2,6 *}$
}

${ }^{1}$ Consejo Nacional de Ciencia y Tecnología (CONACyT), Instituto Nacional de Cancerología (INCan), Mexico City, Mexico; ${ }^{2}$ Joven \& Fuerte: Programa para la Atención e Investigación de Mujeres Jóvenes con Cáncer de Mama, Mexico City, Mexico; ${ }^{3}$ Universidad Nacional Autónoma de México (UNAM), Mexico City, Mexico; ${ }^{4}$ School of Medicine and Public Health, Faculty of Health and Medicine, The University of Newcastle, Callaghan, NSW, Australia; ${ }^{5}$ Research Department, INCan, Mexico City, Mexico; ${ }^{6}$ Breast Cancer Center, Hospital Zambrano Hellion TecSalud, Tecnologico de Monterrey, $\mathrm{NL}$, Mexico

\begin{abstract}
Background: Identifying and addressing breast cancer (BC) patients' unmet needs (UN) are crucial due to their possible contribution to higher levels of morbidity, particularly in vulnerable underserved populations, such as Latinas with BC. Objective: This study aimed to (1) identify and describe the most frequently reported items of moderate-high UN among Mexican women with BC covered by public healthcare insurance; (2) analyze the differences in UN domains according to participants' sociodemographic and clinical characteristics; and (3) validate the Supportive Care Needs Survey-Short Form-34 (SCNS-SF34). Methods: A cross-sectional study was conducted with 396 consecutive BC patients. A linguistically translated and culturally adapted version of the SCNS-SF34 for Mexican women with BC was completed by the participants. Results: The validation yielded a 32-item version of the SCNS with adequate psychometric properties. The Health System and Providers Information was the highest UN domain, followed by the psychological domain. "Fears about cancer spreading" (37.4\%) and "Concerns about the worries of those close to you" (37.3\%) were the most prevalent moderate-high UN. Sexuality was the only domain associated with clinical and sociodemographic characteristics. Conclusion: By defining the most urgent needs of this group of patients, our results will enable the development of targeted support services and patient-centered care. (REV INVEST CLIN. 2021;73(4):245-50)
\end{abstract}

Key words: Breast cancer. Needs assessment. Unmet needs. Mexico.

\section{*Corresponding author:}

Cynthia Villarreal-Garza

E-mail: cynthiavg@gmail.com;

cynthia.villarreal@tecsalud.mx
Received for publication: 29-01-2021

Approved for publication: 06-04-2021

DOI: $10.24875 /$ RIC.21000068

0034-8376 / (c) 2021 Revista de Investigación Clínica. Published by Permanyer. This is an open access article under the CC BY-NC-ND license (http://creativecommons.org/licenses/by-nc-nd/4.0/). 


\section{INTRODUCTION}

It is well known that the diagnosis and treatment of breast cancer (BC) have not only physical but also social, psychological, and spiritual consequences that give rise to supportive care needs ( $\mathrm{SCN}$ ) among patients $^{1}$. In limited-resource settings, like the Mexican public health-care systems cancer care is predominantly focused on providing oncological treatment, bypassing survivorship issues, and supportive care. Thus, the SCN of BC patients are not systematically evaluated or addressed, generating unmet needs (UN) between the services that patients require and the actual care that they receive ${ }^{2,3}$.

Identifying and addressing BC patients' UN - the gap between patients' experience and their requirements - is crucial due to their likely contribution to higher levels of morbidity and impaired transition toward the survivorship phase ${ }^{4}$, particularly in vulnerable underserved populations, such as Latinas with BC, whose low income has been correlated with more UN ${ }^{5}$. The characterization of patients' UN is possible through the use of accurate measures such as the SCN Survey-Short Form-34 (SCNS-SF34), which has been identified as one of the most comprehensive and psychometrically robust cancer-specific tools for assessing $\mathrm{SCN}^{6,7}$.

A Mexican version of the SCNS-SF34 was previously validated with a mixed sample of cancer patients ${ }^{8}$. However, several variables may affect the psychometric properties of an instrument, including the patient population and cross-cultural issues. Therefore, our group developed a culturally adapted and linguistically translated version of the SCNS-SF34 exclusively for Mexican BC patients ${ }^{9}$. Nevertheless, its psychometric properties were not yet evaluated. The availability of an appropriately adapted, translated, and validated instrument in the detection of UN among Mexican patients with $\mathrm{BC}$ is a primordial step to enable the generation of accurate information and to promote the development of useful supportive care services for this population ${ }^{6}$.

In Mexico, until December 2019, approximately 7,328 women with BC rely on the Popular Insurance (Seguro Popular [SP]) program, a major governmental health reform that enabled the most disadvantaged groups to access defined health-care services for certain diseases, including cancer ${ }^{10}$. Since this program mainly covered costs related to medical treatment, it is likely that BC patients receiving care under SP coverage have SCN which should be identified to deliver appropriate interventions to improve their care, treatment results, and quality of life ${ }^{11}$. Therefore, this study aimed to identify and describe the UN most frequently reported by BC patients covered by SP, analyze differences in UN according to sociodemographic and clinical characteristics, and validate the SCNS-SF34 among Mexican women with BC.

\section{METHODS}

\section{Participants}

Consecutive patients diagnosed with $\mathrm{BC}, \geq 18$ years, treated at the National Cancer Institute (Instituto Nacional de Cancerología [INCan]) in Mexico City, and covered through SP were eligible. Exclusion criteria were refusal to participate and the presence of repeated data or incomplete answers to the survey's questions.

From June 2015 to August 2016, 450 BC patients were invited to participate. Of these, 396 consented, $40(10 \%)$ refused by referring that they did not have time or interest in participating, and 14 (3\%) were excluded due to inaccuracies in data recording not related to patients' acceptability. Of note, in a previous report that assessed the cultural adaptation of the SCNS-SF34, patients stated that they felt comfortable with all the survey's items ${ }^{9}$.

Patients' mean age was 49 years $(S D=11.2)$ and mean time since diagnosis was 34 months $(S D=37)$. In total, $70 \%$ had completed middle-high school education, $62 \%$ were unemployed, and $91 \%$ belonged to a low socioeconomic level. Most patients were not their household's main financial provider. The most frequent BC clinical stages were III-IV. Most participants had already started cancer therapy and were receiving active treatment at the time of the survey (Supplemental Table 1).

\section{Instrument}

The SCNS-SF34 measures cancer patients' perceptions of SCN across five domains: psychological, 
health system and information, physical and daily living (PDL), patient care and support (PCS), and sexuality. Patients indicate their need for help over the past month as a result of having cancer on a 5-point Likert scale with the following response options: $1=$ no need, not applicable; 2 = no need, satisfied; 3 = low need; 4 = moderate need; and $5=$ high need. A standardized domain score ranging from 0 to 100 can then be calculated, with higher scores reflecting greater levels of UN. In the original validation study, the five factors accounted for $72.1 \%$ of the total variance, and the internal reliability coefficients exceeded 0.8 for all domains ${ }^{6}$. This study used the linguistically translated and culturally adapted SCNS-SF34 version for Mexican BC patients ${ }^{9}$. Clinical and sociodemographic characteristics were obtained from participants' clinical records.

\section{Procedure}

In this cross-sectional study, potentially eligible patients were identified and given a verbal explanation of the study's objectives and data confidentiality. All those who agreed to participate provided their written informed consent. To maximize standardization, the SCNS-SF34 was completed by a trained research psychologist through a face-to-face interview in a private office ${ }^{8}$. Participants' responses for each item of the survey were recorded. All personal data were kept private and confidential. This study was approved by the Ethics and Research Review Board of INCan.

\section{Statistical Analysis}

\section{Psychometric evaluation of SCNS-SF34}

Four analyses were performed ${ }^{12}$ : (1) item discrimination was assessed with the Mann-Whitney U-test ( $p$ $<0.05$ ); (2) Cronbach's alpha coefficient evaluated the scale's reliability; (3) factorial validity was evaluated using principal components factor analysis with the criteria for factorial validity ${ }^{13}$; and (4) confirmatory factor analyses (CFAs) to empirically explore the factor structures shown in the exploratory factor analysis (EFA). The sample size was calculated based on five patients for each of the original survey's 34 items ${ }^{12}$.

\section{Prevalence and correlates of UN}

A standardized Likert summated score was calculated for each domain to identify those of highest and lowest UN ${ }^{14}$. The most prevalent UN were identified by calculating the percentage of patients that endorsed each item at a moderate-high level. The Mann-Whitney $U$-test was used to compare differences between domains by sociodemographic and clinical variables. A two-tailed $p<0.05$ was considered significant. Statistical procedures were conducted using SPSS $22 \mathrm{~J}$.

\section{RESULTS}

\section{Internal Structure and Psychometric Evidence}

According to EFA, using principal components analysis with Varimax rotation, Bartlett's test statistic for the significance of the correlation matrix was appropriate $(7,379.601, p=0.0001)$. Sample adequacy was confirmed by the Kaiser-Meyer-Olkin statistic of 0.922 . The factor analysis resulted in a three-factor solution (health system and providers and information [HSPI], psychological, and PDL), and two indicators comprised less than 3 items each (sexuality and PCS choice [PC$\mathrm{SCh}]$ ). This version obtained 32 items, which accounted for $60.1 \%$ of the total variance (Supplemental Tables 2 and 3 ).

The model obtained by the CFA showed good adjustment, as indicated by the following values: $\mathrm{CMIN} / \mathrm{df}=$ 1.987, $\mathrm{p}=0.000 ; \mathrm{NFI}=0.883 ; \mathrm{GFI}=0.874 ; \mathrm{CFI}=$ 0.938 ; and RMSEA $=0.05$, with a $95 \%$ confidence interval between 0.045 and 0.055 . The resulting SCNS-SF32 for Mexican BC patients demonstrated satisfactory internal consistency, with Cronbach's alpha of 0.70. Cronbach's alphas for the domains were ranged 0.94-0.75 (Supplemental Table 3).

\section{Prevalence and Correlates of UN}

Based on the factor structure found in this study, UN were highest in the HSPI domain, followed by psychological and PDL. In contrast, UN were lowest in the PCSCh domain (Supplemental Table 4). The two main items rated as moderate-high UN were "Fears about the cancer spreading" and "Concerns about the worries of those close to you." Women with $\leq 12$ months 
since diagnosis reported significantly more HSPI needs ( $p=0.02)$ than those with $>12$ months. Sexuality needs were significantly different according to several sociodemographic and clinical characteristics. Patients who reported more sexuality UN were $<50$ years $(p=0.007)$; married ( $\leq \leq 0.0001)$; had middlehigh school education ( $p=0.0452)$; their $B C$ treatment was sponsored by others (not by themselves) $(p=0.021)$; and had already undergone chemotherapy $(p=0.03)$ or were on active treatment $(p=$ 0.02) (Supplemental Table 1).

\section{DISCUSSION}

This validation's explained variance was acceptable, as has been argued in other studies with similar versions (among other BC patients) and with consistent results ${ }^{6,15-17}$. Although our construct validity was lower than that of the Japanese version, it was superior to the Chinese adaptation and the Mexican version for cancer patients in general ${ }^{8,15-17}$. Of note, other authors have previously proposed that the size of variance might be influenced by other cancer-specific needs which are not evaluated in this more general instrument ${ }^{15}$. Furthermore, the reliability coefficient of the present validation was similar to those reported in the original and the Mexican, French, Japanese, Chinese and earlier versions ${ }^{6,8,15-17}$.

At the domain level, HSPI exhibited the highest UN. This finding is consistent with those reported in other studies with young Mexican women, Chinese, and low-income Latinas with $\mathrm{BC}^{5,15,18,24}$. Patients' lack of information might be partially explained by the existence of barriers to access information and inadequate patient-physician communication ${ }^{3}$. Given that the main $U N$ is related to information, our research group has dedicated efforts to develop materials that can be used by Spanish-speaking patients, and we are assessing their impact on the needs ${ }^{19}$.

Opposingly, our study found that PCSCh UN were the lowest. This contrasts with other studies evaluating Mexican cancer patients and young women with $\mathrm{BC}$ which reported sexuality as the domain of the lowest need $^{8,24}$. The different phases of the cancer trajectory in which each sample was, might be correlated to these discrepancies between studies ${ }^{1}$. In the present study, as well as in the study evaluating young
Mexican women, most patients already received or were receiving active treatment and might, therefore, be more concerned about their medical team choices and treatment recommendations, which explains why information needs are the most unsatisfied ${ }^{24}$.

This study also found that patients with $\leq 12$ months since diagnosis had higher HSPI scores than those with $>12$ months. These results are consistent with those observed in other Mexican patients ${ }^{18}$ and confirm that recently diagnosed cancer patients have greater information needs than those in later phases of treatment or survivorship ${ }^{20}$. As previously reported, a recent $\mathrm{BC}$ diagnosis poses physical, emotional, social, psychological, and informational challenges that require patients to seek and learn new skills, and to reach out to other people to meet these new needs ${ }^{1}$.

Interestingly, sexuality was the only domain associated with clinical and sociodemographic characteristics. Being younger and receiving chemotherapies were associated with higher levels of sexuality needs. In line with this observation, other studies have described that sexual dysfunction is especially prominent among young women, who are more vulnerable to chemotherapy-related changes in ovarian function ${ }^{21}$. The association between having a partner and higher sexuality UN has also been previously described and could be related to the changes and repercussions of a cancer diagnosis on intimate relationships with active sexual lives ${ }^{2,8,11,18}$. Likewise, not being the household's main financial provider and having a higher schooling were also associated with higher sexuality needs ${ }^{8}$, but their specific causes have not been elucidated.

At the item level, "Fears about cancer spreading" and "Concerns about the worries of those close to you" were the most frequently reported moderate-high UN, which is consistent with several studies among low-income Latinas and young Mexican BC patients, as well as with Japanese, German, and French women with $\mathrm{BC}^{5,16,17,24}$, rural populations ${ }^{6}$, among others. These findings could reflect the magnitude of the psychological impact associated with recurrence (regardless of stage), treatment trajectory, culture, or other sociodemographic variables ${ }^{7}$. Concerning the fear of recurrence UN, we are culturally adapting interventions, which have shown to be effective ${ }^{22}$, and consequently exploring their effectiveness. 
This study has some limitations that should be considered. Mainly, these results correspond to BC patients from a single Mexican health care institution. However, it is important to point out it represents the main cancer referral center in the country and receives BC patients from several states. Likewise, the study only included patients with governmental health-care insurance. Nonetheless, these findings could be applicable to other Mexican contexts and Latin American countries as nearly half of the population is covered by similar public health-care systems ${ }^{23}$. Another limitation of this study is related to the unfeasible self-administration of the survey due to participants' low literacy levels ${ }^{8}$, and applying the survey through face-to-face interviews may have led to social desirability response bias.

In conclusion, this study showed that the culturally adapted and linguistically translated SCNS-SF32 for Mexican BC patients has good psychometric properties and is paramount for the identification of their most pressing needs. Moreover, due to the urgency of recognizing and providing supportive care to this population, the availability of the first version in Spanish specifically for BC patients is of utmost importance as it represents a valuable tool and model for other Spanish-speaking countries, which lack validated versions specific to their populations.

Furthermore, this study is the first to explore the SCN of disadvantaged BC patients in Latin America. Given that the assessment of SCN is a crucial step in the development and delivery of appropriate interventions that can improve BC patients' quality of life, the SCNS-SF32 will enable a better understanding of the services that should be provided to these patients and optimize the care provided by health-care systems. Our findings suggest that supportive care mainly targeting these patients' needs related to the healthcare system, providers, and information delivery, especially among those who are more recently diagnosed, is a priority to develop directed support services and offer patient-centered care.

\section{ACKNOWLEDGMENTS}

We thank Oliver Lamping, BS (Bright Hope Church, Reading, Berkshire, UK; Child Social Care: Bracknell Forest Council, Bracknell, Berkshire, UK); Deborah D.
Aleman Hoey, MD (Instituto Nacional de Ciencias Médicas y Nutrición Salvador Zubirán, Mexico City, Mexico); Diana V. Castillo Padilla, PhD (Child Psychology and Brain Stimulation Association, Mexico City, Mexico); and Antonio Anzures Bolaños, DC (Mexican Society of Calligraphers and Illuminators, Mexico City, Mexico), for their assistance with the translation of the survey.

\section{SUPPLEMENTARY DATA}

Supplementary data are available at Revista de Investigación Clínica online (www.clinicalandtranslationalinvestigation.com). These data are provided by the corresponding author and published online for the benefit of the reader. The contents of supplementary data are the sole responsibility of the authors.

\section{REFERENCES}

1. Fitch MI, Gray RE, Godel R, Labrecque M. Young women's experiences with breast cancer: an imperative for tailored information and support. Can Oncol Nurs J. 2008;18:74-86.

2. Pérez-Fortis A, Fleer J, Schroevers M, Alanis-López P, SánchezSosa J, Eulenburg C, et al. Course and predictors of supportive care needs among Mexican breast cancer patients: a longitudinal study. Psychooncology. 2018;27:2132-40.

3. Villarreal-Garza C, López-Martínez E, Martínez-Cannon B, Platas A, Castro-Sánchez A, Miaja M, et al. Medical and information needs among young women with breast cancer in Mexico. Eur ] Cancer Care. 2019;28:e13040.

4. Costanzo ES, Lutgendorf SK, Mattes ML, Trehan S, Robinson C, Tewfik F, et al. Adjusting to life after treatment: distress and quality of life following treatment for breast cancer. $\mathrm{Br}$ ]. 2007;97:1625-31.

5. Sleight AG, Lyons KD, Vigen C, Macdonald H, Clark F. Supportive care priorities of low-income latina breast cancer survivors. Support Care Cancer. 2018;26:3851-9.

6. Boyes A, Girgis A, Lecathelinais C. Brief assessment of adult cancer patients' perceived needs: development and validation of the 34-item supportive care needs survey (SCNS-SF34). J Eval Clin Pract. 2009;15:602-6.

7. Harrison JD, Young JM, Price MA, Butow PN, Solomon MJ. What are the unmet supportive care needs of people with cancer? A systematic review. Support Care Cancer. 2009;17:1117-28.

8. Doubova SV, Aguirre-Hernandez R, Gutiérrez-de la Barrera M, Infante-Castañeda C, Pérez-Cuevas R. Supportive care needs of Mexican adult cancer patients: validation of the Mexican version of the short-form supportive care needs questionnaire (SCNSSFM). Support Care Cancer. 2015;23:2711-9.

9. Gálvez-Hernández CL, Oñate-Ocaña LF, Mohar-Betancourt A, Boyes A, Neri-Flores V, Villarreal-Garza C. Cultural adaptation process of the supportive care needs survey for Mexican patients with breast cancer. Lat Am J Behav Med. 2019;9:13-20.

10. Comisión Nacional de Protección Social en Salud (CNPSS). Informe de Resultados del Sistema de Protección Social en Salud EneroJunio 2019. Ciudad de Mexico; 2019. Available from: http://www. transparencia.seguro-popular.gob. $\mathrm{mx} /$ contenidos/archivos/ transparencia/planesprogramaseinformes/informes/2018/InformedeResultadosdelSPSSenero junio2019.pdf.

11. Schmid-Büchi S, Halfens RJ, Müller M, Dassen T, van den Borne B. Factors associated with supportive care needs of patients under treatment for breast cancer. Eur J Oncol Nurs. 2013;17:22-9.

12. Nunnally J, Bernstein I. Psychometric Theory. 3rd ed. New York: McGraw-Hill; 1994.

13. DeVellis, R. Scale Development Theory and Applications. 4th ed. Thousand Oaks, California: Robert, Sage Publication; 2017. 
14. McElduff P, Boyes A, Zucca A, Girgis A Supportive Care Needs Survey: a Guide to Administration, Scoring and Analysis. New Castle: AUST Abbottabad University of Science; 2004.

15. Au A, Lam WW, Kwoong A, Suen D, Tsang J, Yeo W, et al. Validation of the Chinese version of the short-form supportive care needs survey questionnaire (SCNS-SF34-C). Psychooncology. 2011;20:1292-300.

16. Brédart A, Kop JL, Griesser AC, Zaman K, Panes-Ruedin B, Jeanneret $W$, et al. Validation of the 34 -item supportive care needs survey and 8-item breast module french versions (SCNS-SF34$\mathrm{Fr}$ and SCNS-BR8-Fr) in breast cancer patients. Eur J Cancer Care. 2012;21:450-9.

17. Okuyama T, Akechi T, Yamashita H, Tomaya T, Endo C, Sagawa $\mathrm{R}$, et al. Reliability and validity of the Japanese version of the short-form supportive care needs survey questionnaire (SCNSSF34-J). Psychooncology. 2009;18:1003-10.

18. Pérez-Fortis A, Fleer J, Sánchez-Sosa JJ, Veloz-Martínez MG, Alanis-López P, Schroevers MJ, et al. Prevalence and factors associated with supportive care needs among newly diagnosed Mexican breast cancer patients. Support Care Cancer. 2017; 25:3273-80.
19. Médicos e Investigadores en la Lucha Contra el Cáncer de Mama MILC. Available from: https://www.milc.org.mx.

20. Jing $L$, Zhang $C$, Li W, Jin F, Wang A. Incidence and severity of sexual dysfunction among women with breast cancer: a metaanalysis based on female sexual function index. Support Care Cancer. 2019;27:1171-80.

21. Chang YC, Chang SR, Chiu SC. Sexual problems of patients with breast cancer after treatment: a systematic review. Cancer Nurs. 2019;42:418-25.

22. Lebel S, Maheu C, Lefebvre M, Secord S, Courbasson C, Singh M et al. Addressing fear of cancer recurrence among women with cancer: a feasibility and preliminary outcome study. J Cancer Surviv. 2014;8:485-96.

23. Latin America Healthcare System Overview: a Comparative Analysis of Fiscal Space in Healthcare; 2019. Available from: https://www.lse.ac.uk/business-and-consultancy/consulting/ assets/documents/latin-america-healthcare-system-overviewreport-english.pdf

24. Galvez-Hernández L, Ortega A, Villarreal-Garza C, del Río BR. Mujeres jóvenes con cáncer de mama: necesidades de apoyo en la atención y resiliencia. Psicooncología. 2018;15:287-300. 